\section{EI IAPH concluye los trabajos de conservación de la antigua capilla del Palacio de San Telmo}

El Instituto Andaluz del Patrimonio Histórico dio por concluidos el pasado mes de febrero los trabajos de conservación de los bienes muebles de la antigua capilla del Palacio de San Telmo. Este proyecto, en el que se han invertido siete años de investigación y actuaciones, se ha convertido en el de mayor envergadura de los abordados por el IAPH en materia de conservación y restauración del patrimonio cultural desde su creación en 1989, y el primero de estas características que se plantea desde un sistema de gestión integral por procesos, correspondiendo su desarrollo íntegro al Centro de Intervención en el Patrimonio Histórico. a ser diseñado y construido por el gran arquitecto barroco Leonardo de Figueroa.

Asimismo es uno de los pocos espacios del palacio que ha llegado virtualmente intacto hasta nosotros. Tanto su arquitectura como su dotación artística permanecen prácticamente inalterables. Es más, en la capilla se superponen de forma armoniosa los sucesivos programas decorativos que fueron diseñados por la Universidad de Mareantes (siglo XVIII) y por los Duques de

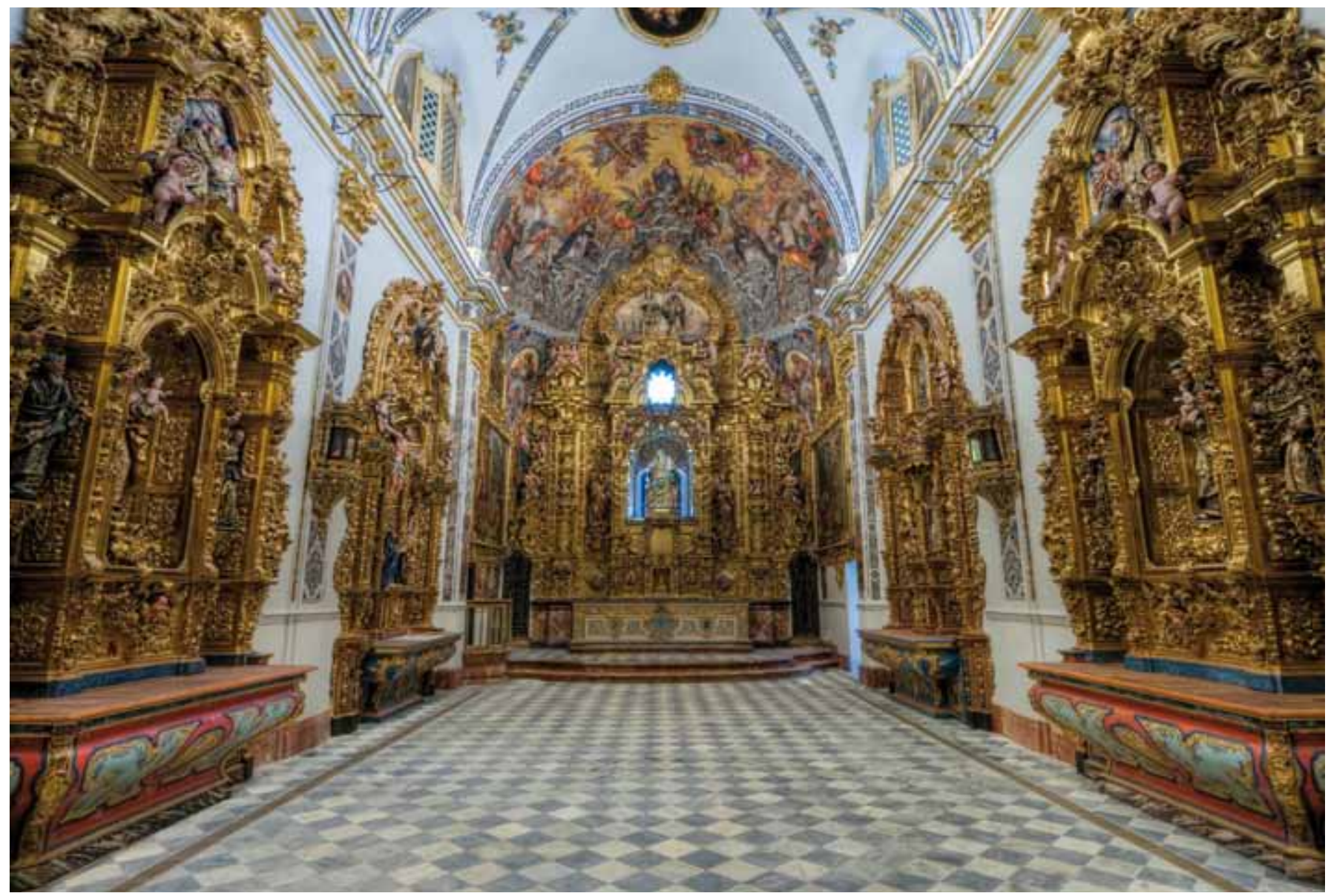

Antigua capilla del Palacio San Telmo. Estado tras los trabajos de intervención del IAPH (2003-2010). Foto: José Manuel Santos Madrid, IAPH

Recientes aportaciones cientificas de historiadores de arte y de la arquitectura han puesto de manifiesto la importancia patrimonial del edificio que actualmente conocemos como Palacio San Telmo, así como el significado que el mismo tiene para la historia del arte andaluz y su papel como referente social e institucional en nuestra $\stackrel{\frac{\pi}{U}}{\frac{\pi}{L}}$ Comunidad durante siglos.
Los avatares históricos de la construcción del edificio y su patrimonio cada vez son mejor conocidos. Sabemos que en el plan del proyecto arquitectónico, la capilla ocupaba un lugar importante en razón del programa de usos que el Real Colegio de San Telmo (formación de marinos profesionales) había dado al edificio. También sabemos que es el único ámbito del palacio que llegó
Montpensier (siglo XIX) y ambos han llegado hasta nosotros. Se trata, pues, de una joya del arte andaluz y español.

Con esta premisa cultural, la lla fase del programa de conservación y restauración del palacio San Telmo diseñado por la Consejería de Economía y Hacienda incorporó la necesidad de restaurar la capilla y su hermo- 
so patrimonio histórico. A tal fin, se encargó en octubre de 2003 al Instituto Andaluz del Patrimonio Histórico la realización de los estudios correspondientes. El Centro de Intervención en el Patrimonio Histórico actuó, en función de los valores artísticos de la colección y del evidente deterioro que la misma presentaba como consecuencia de la falta de mantenimiento y conservación que durante años había padecido.

El estado de conservación de la colección artística fue calificado como de deficiente. Varias eran las razones que justificaban ese calificativo. De una parte la degradación estética de la colección como consecuencia de las acciones antrópicas durante todo el siglo XX (Seminario Diocesano). En este sentido cabe indicar que varias obras de arte habian sido objeto de incalificables actuaciones de repintados industriales que ocultaban totalmente sus valores culturales y modificaban su aspecto exterior.

Una segunda razón era causa de la falta de mantenimiento de la colección. Ello había llevado a la misma a un deterioro material muy considerable: roturas, desgarros y desprendimientos caracterizaban otro buen grupo de patologías.

Por último, la colección presentaba daños inherentes a la falta de conservación del edificio, que se habian transmitido fundamentalmente a las magnificas pinturas murales del siglo XVIII y las pinturas de la galería nueva, y que habian provocado una lectura estética incorrecta como consecuencia de las grandes pérdidas de superficie pictórica, repintes generalizados y oxidaciones de barnices que presentaban dichas pinturas.

Por estas razones fue decidida la redacción de un Proyecto de Conservación de los Bienes Muebles de la antigua capilla del Palacio que:

a) diera respuesta a las necesidades de conservación de todas y cada una de los dos centenares de obras de arte y objetos artis- ticos instalados en el mismo, independientemente de su soporte;

b) permitiera la recuperación del programa iconográfico original de la antigua capilla y de la lectura artística de la misma conforme a los postulados conceptuales y estéticos para los que fue concebida;

c) garantizara la musealización del espacio al convertirlo en uno de los puntos esenciales del discurso cultural del palacio y consecuentemente accesible a la visita pública;

d) formulara directrices para el mantenimiento futuro de la colección artística.

El proyecto aprobado por la citada Consejería de Economía y Hacienda ha sido ejecutado por el IAPH entre diciembre de 2003 y la actualidad.

\section{El proyecto ha procurado la} recuperación del programa iconográfico original de la antigua capilla y su lectura artística conforme a los postulados conceptuales y estéticos con los que fue concebida

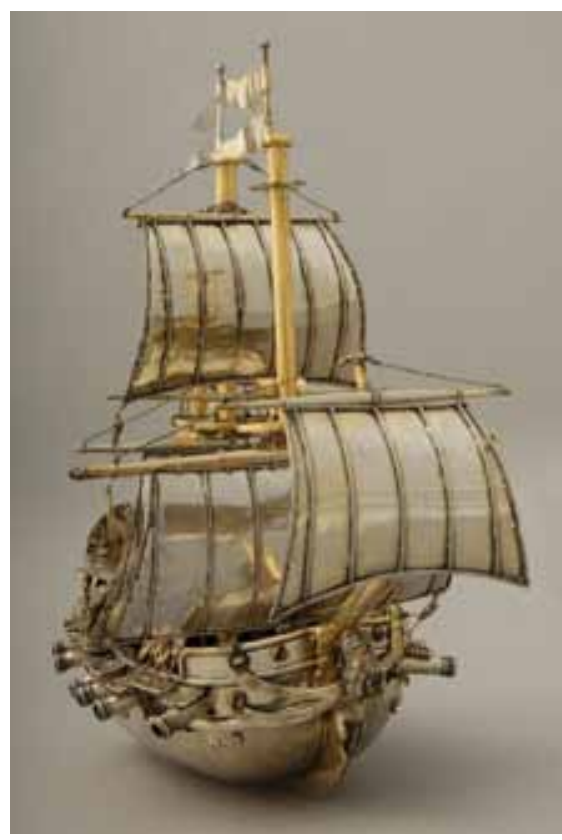

Galeón de la Virgen del Buen Aire (Juan de Garay, 1725). Foto: José Manuel Santos Madrid, IAPH

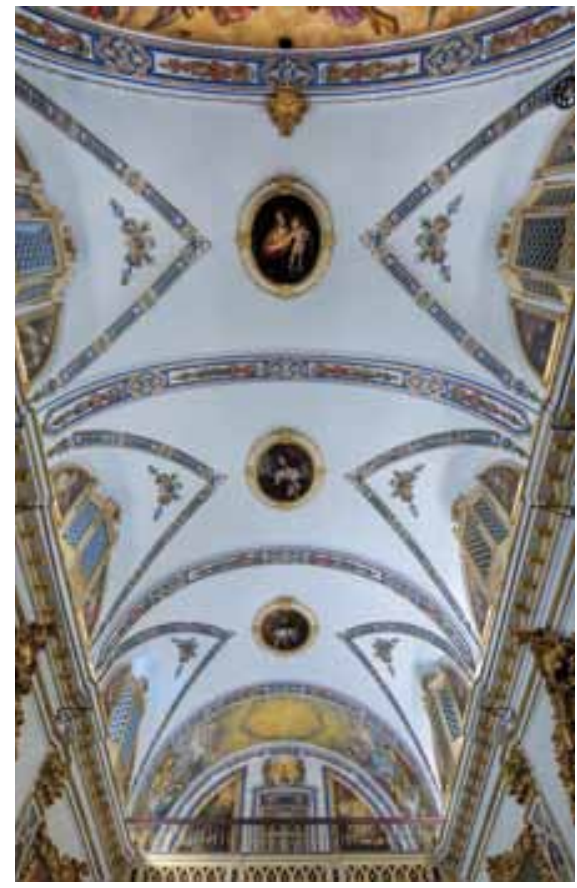

Bóveda de la capilla y programa iconográfico época romántica, 1850. Foto: José Manuel Santos Madrid, IAPH

La colección sobre la que ha actuado el Instituto Andaluz del Patrimonio Histórico está formada por:

- $350 \mathrm{~m}^{2}$ de pinturas murales de los siglos XVIII y XIX.

- 5 retablos del siglo XVIII.

- 27 marcos en madera tallada y dorada de los siglos XVIII y XIX.

- 3 vitrinas con esculturas de los siglos XVII y XVIII.

- 6 miradores con celosías policromadas del siglo XIX y un cancel del siglo XVIII.

- 43 esculturas en madera tallada y policromada de los siglos XVI, XVII, XVIII y XIX.

- 1 escultura en plomo policromada del siglo XVII.

- 28 pinturas al óleo sobre lienzo de los siglos XVIII y XIX.

- $100 \mathrm{~m}^{2}$ de pintura al temple sobre lienzo del siglo XIX.

- 10 obras de platería del siglo XVIII.

- 3 documentos gráficos del siglo XIX.

- 1 pieza textil del siglo XVIII.

- 3 conjuntos cerámicos formados por 4.700 piezas de los siglos XVIII al XX.

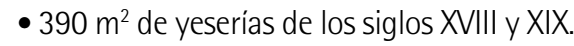

- 86 piezas de forja y latonería de los siglos XVIII y XIX. 


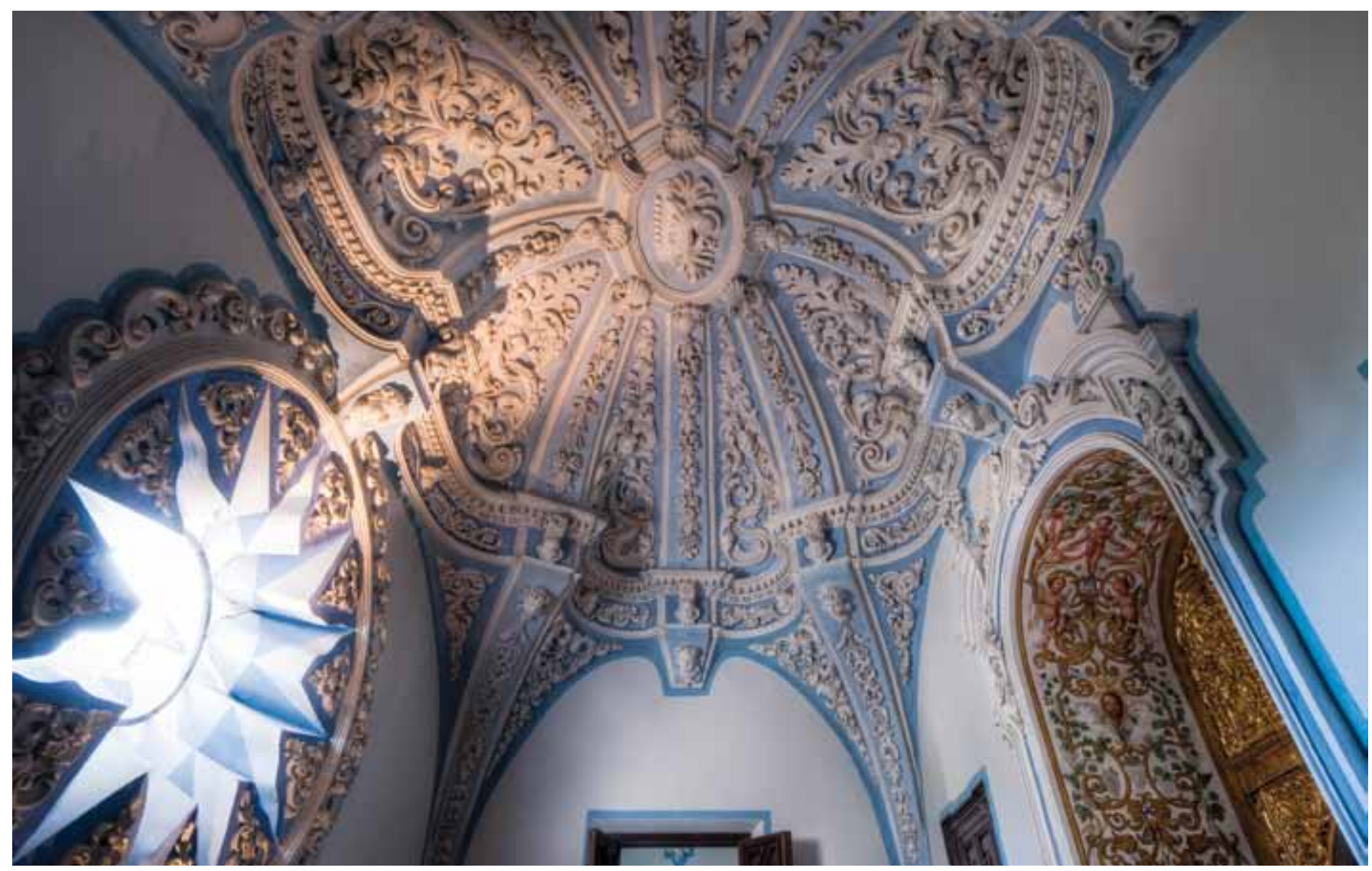

Bóveda con decoración de yeserías en el camarín alto (Antonio Matías de Figueroa y Domingo Martínez, 1724-5). Foto: José Manuel Santos Madrid, IAPH

La actuación del IAPH

ha tenido como directriz

el respeto íntegro del

monumento como

documento histórico

Además se ha redactado un programa de mantenimiento de la colección y seguimiento de las condiciones medioambientales de la capilla. A finales de 2010 está prevista la publicación de la Memoria de intervención dentro de la serie Cuadernos Técnicos del IAPH.

La labor científica de los historiadores del arte ha sido particularmente fructífera documentándose obras inéditas de artistas tan relevantes como el arquitecto Matías de Figueroa, el pintor barroco Domingo Martínez, el escultor Miguel de Perea, el entallador Miguel de Quintana y el artista madrileño Vicente López; pintor

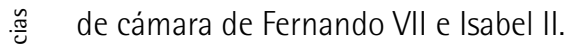

La información generada por el proyecto asciende a más de 8.000 fotografías y casi 4.000 páginas de información técnica y científica que pronto estarán a disposición de los estudiosos e investigadores.

El proyecto se ha ejecutado observando criterios de conservación científica del patrimonio mueble sustentados en el conocimiento histórico y científico del bien y en el valor patrimonial de los objetos. La actuación del IAPH ha tenido como directriz el respeto integro del monumento como documento histórico, y el respeto a la imagen de antigüedad del mismo y de cada una de sus partes integrantes.

No obstante, la compleja heterogeneidad de los soportes materiales de los elementos artisticos existentes en la antigua capilla, ha exigido el despliegue, dentro del mismo proyecto, de dos variables conceptuales de la conservación científica del patrimonio mueble, que han sido:
- Criterio arqueológico, que se ha aplicado, básicamente, a la arquitectura lignaria. En este ámbito ha primado la conservación de las características esenciales, es decir, donde la recuperación formal o volumétrica del monumento no ha sido admitida, y solo se ha permitido la consolidación mínima y notoria.

- Criterio pictórico, que ha sido el aplicado a las pinturas murales y elementos decorativos singulares (mesas de alter, balcones...) y que ha tenido como objetivo mantener las características históricoestéticias del monumento, y se enfoca en recuperar los valores artísticos, pictóricos y compositivas del mismo, buscando la unidad estético-formal de cada parte y de todas entre sí, incluyendo la recuperación de la lectura de los programas iconográficos que se despliegan en la antigua capilla.

\section{Lorenzo Pérez del Campo}

Jefe del Centro de Intervención en el Patrimonio Histórico 